\title{
Corrosion Inhibition performance of polyethylene glycol/ polytriethanolamine inhibitors on corrosion of carbon steel in acidic medium
}

\author{
Nabel A. Negm ${ }^{1 \#}$, Ahmad F. El Farargy ${ }^{2}$, Emad A. Badr ${ }^{1}$, Mohamad F. Zaki ${ }^{1}$ \\ ${ }^{1 .}$ Petrochemicals Department, Egyptian Petroleum Research Institute, Cairo, EGYPT \\ 2. Chemistry department, Zagazig University, Zagazig, EGYPT.
}

\begin{abstract}
The inhibition effect of three nonionic inhibitors on carbon steel corrosion in $1 \mathrm{M} \mathrm{H}_{2} \mathrm{SO}_{4}$ was studied gravimetrically and electrochemically. Increasing the number of triethanolamine units in the inhibitor molecules increases their inhibition efficiencies. The inhibiting action of inhibitors was attributed to their adsorption on the carbon steel surface and the formation of dense protective layer which increased by increasing their concentration. Polarization measurements showed that inhibitors act as mixed-type inhibitor in $1 \mathrm{M} \mathrm{H}_{2} \mathrm{SO}_{4}$ with a domain of anodic one, and their inhibition on carbon steel proceeded by physical adsorption. Increasing the surface activity of inhibitors increased their inhibition efficiency
\end{abstract}

Keywords: A. Carbon steel, B. Polarization, B. Weight loss, C. Acid inhibition

\section{Introduction}

The study of iron and iron alloys corrosion phenomena has become important particularly in acidic media because of the increased industrial applications of acid solutions. As an example, the refining of crude oil results in a variety of corrosive conditions. Refinery corrosion is generally caused by a strong acid attacking the equipment surface [1]. The other important fields of applications are acid pickling, industrial cleaning, acid descaling, oil-well acid in oil recovery and the petrochemical processes [2]. Among the acid solutions, mineral acids including $\mathrm{H}_{2} \mathrm{SO}_{4}$ and $\mathrm{HCl}$ are the most widely used acids. Due to the exposure of steel to corrosive environments, they are susceptible to different types of corrosion mechanisms. The use of corrosion inhibitors to prevent metal dissolution is therefore essential. Large numbers of organic compounds were studied to investigate their corrosion inhibition potential. For example, the effect of organic nitrogen compounds on the corrosion behaviour of iron and steel in acidic solutions is employed for their corrosion inhibiting action [3-10]. Recently, the application of surfactants as effective corrosion inhibitors has attracted the attention of many researchers. The adsorption of the surfactant molecules through their hydrophilic head changes the corrosion resistance property of the metal. The inhibitor efficiency depends on the metal type, inhibitor concentration [1120], chemical structure of surfactant [14], $\mathrm{pH}$ [21], temperature [22, 23], type of acid [23], immersion time [11, 24] and the presence of co-surfactant [25-28]. Surfactants as organic inhibitors are unique due to their special chemical and surface properties [29-31]. Ionic and non-ionic surfactants have been reported as corrosion inhibitors for various groups of metals, such as copper, aluminium, and mild-steel [32-35]. Non-ionic surfactants in particular where the polar head group is without charge are known to have many applications through industry, including cosmetics, detergents, and also as corrosion-inhibitors. In addition to these valuable properties, they can be mixed with other types of surfactants, e.g., anionic or cationic, to enhance their properties, and reduce surfactant precipitation [36-39]. This class of surfactants has substantially lower critical micelle concentrations $\mathrm{CMC}$, than the corresponding ionic surfactants. That enriches their applicability as corrosion inhibitors. Surfactants exert the inhibition action by adsorption on the metal surfaces such that chemical structure of the ionic head (hydrophilic part) attacks the metal surface while its tail (hydrophobic part) extends to the solution face. The influence of the chemical structure of ionic head on inhibition efficiency was extensively studied $[14,26,27,30,40]$. In this study, the corrosion inhibition performances of three nonionic environmentally friendly surfactants (labelled as $\mathrm{P}_{8}, \mathrm{P}_{10}$ and $\mathrm{P}_{12}$ ) for carbon steel corrosion in $1 \mathrm{M}_{2} \mathrm{SO}_{4}$ solutions were investigated by weight loss and electrochemical techniques. The aim of this work is to assess the inhibition effectiveness of $\mathrm{P}_{8}, \mathrm{P}_{10}$ and $\mathrm{P}_{12}$ inhibitors on the carbon steel corrosion in $1 \mathrm{M} \mathrm{H}_{2} \mathrm{SO}_{4}$ solutions and to explore interaction mechanism between the inhibitor molecules and the carbon steel surface.

Synthesis of inhibitors

\section{Experimental}

Polytriethanolamine was prepared by condensation polymerization of triethanolamine in presence of $\mathrm{NaOH}$ as a catalyst at $245{ }^{\circ} \mathrm{C}$ for different time interval of 3,4 , and 6 hours to produce three polytriethanol 
amine polymers containing eight, ten and twelve triethanolamine units in the polymeric chain. [41]. Figure 1 represents the synthetic steps of the different polytriethanolamine polymers.

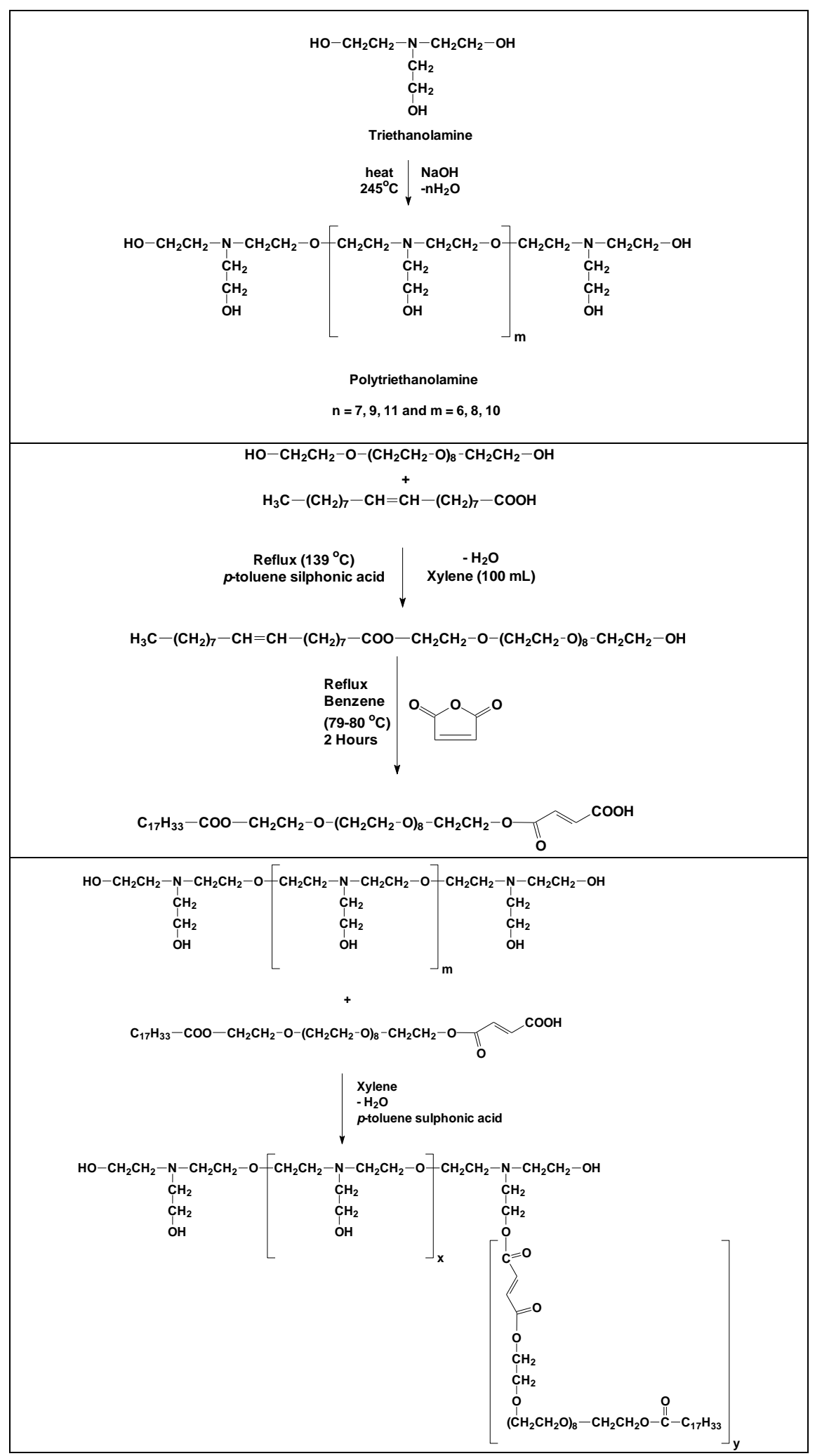

Figure 1: Synthesis of the inhibitors; $P_{8}: x=6, y=2 ; P_{10}: x=8, y=3 ; P_{12}: x=10, y=4$. 
0.21 mole of polyethylene glycol $\left(\mathrm{Mw}=400 \mathrm{~g} \mathrm{~mol}^{-1}\right)$ and 0.2 mole of oleic acid $(28.2 \mathrm{~g})$ were esterified individually under reflux conditions in the presence of $100 \mathrm{~mL}$ of xylene as a solvent and $0.1 \%$ by weight of p-toluene sulphonic acid as a dehydrating gent. The reaction was stopped when the theoretical amount of the water produced from the reaction $(3.6 \mathrm{~mL})$ was obtained. Then the solvent was removed under reduced pressure. The reaction product was dissolved in petroleum ether $(250 \mathrm{~mL})$ and then $100 \mathrm{~mL}$ of distilled water was added. The aqueous layer which contains the catalyst and the excess polyethylene glycol was separated by separating funnel and the ether layer was evaporated to obtain the polyethylene glycol/monooleate ester. Then, 0.2 mole of polyethylene glycol-monooleate was reacted by $0.2 \mathrm{~mol}$ of maleic anhydride in the presence of 150 $\mathrm{mL}$ of benzene as a solvent under continuous stirring. The reaction was followed by IR spectroscopy and was deemed complete at the point of disappearance of the anhydride linkage at $1850 \mathrm{~cm}^{-1}$. The reaction product was dissolved in $200 \mathrm{~mL}$ (50:50 vol.) of ethyl acetate/diethyl ether mixture. The ethyl acetate layer contains the diester and the unreactants dissolved in diethyl ether layer. The lower layer was separated by separating funnel, and the solvent was evaporated under reduced pressure to obtain the desired ester.

Polymerized triethanolamine polymers were esterified individually by different molar amounts of polyethylene glycol-oleic-maleic anhydride ester in a sufficient amount of xylene and $0.1 \%$ by weight of ptoluene sulphonic acid under reflux condition until the theoretical amount of water was obtained. The product was washed with a hot supersaturated sodium chloride solution. Then the organic layer which contains the products was separated and the solvent was distilled off under vacuum [41]. The obtained inhibitors were designated as $\mathrm{P}_{8}, \mathrm{P}_{10}$, and $\mathrm{P}_{12}$ as represented in Figure 1.

\section{Weight loss method}

Weight loss measurements were performed using carbon steel samples with a rectangular form with a total area of $37 \mathrm{~cm}^{2}$ in $1 \mathrm{M} \mathrm{H}_{2} \mathrm{SO}_{4}$ solution in the presence and absence of $\mathrm{P}_{8}, \mathrm{P}_{10}$ and $\mathrm{P}_{12}$ inhibitors at concentrations of 400, 200, 100, 50 and $25 \mathrm{ppm}$ by weight. The inhibitors were completely soluble in the acidic medium with no precipitation or coagulation. Tests were performed on carbon steel of the following composition (wt.\%): $0.11 \% \mathrm{C}, 0.45 \% \mathrm{Mn}, 0.04 \% \mathrm{P}, 0.05 \% \mathrm{~S}, 0.25 \% \mathrm{Si}$ and the remainder is Fe. Before the measurements, the carbon steel specimens were immersed in $1 \mathrm{M} \mathrm{HCl}$ solution for $10 \mathrm{~s}$ to remove the oxide layer on their surface (chemical method to remove rust products), then washes by distilled water and dried. Finally, they were abraded by 180, 400, 600, and 1200 grades of emery paper, degreased with acetone, and washed by distilled water two times and finally dried. After weighed accurately, each sample was suspended statically in the deaerated acid solution $(500 \mathrm{~mL})$ using glass hock and for different immersion time intervals of $1,3,6$ and $24 \mathrm{~h}$ in thermostatically controlled temperature at $25{ }^{\circ} \mathrm{C}$. Then, the surface of each specimen was cleaned by double distilled water followed by rinsing in acetone, dried and weighed to calculate the loss in weight (w) of each specimen. For each experiment, a freshly prepared solution was used, and the solution temperature was thermostatically controlled. The aggressive solutions $\left(1 \mathrm{M} \mathrm{H}_{2} \mathrm{SO}_{4}\right)$ were prepared by diluting analytical grade of $\mathrm{H}_{2} \mathrm{SO}_{4}$ in double distilled water. The corrosion rate $\left(\mathrm{C}_{\mathrm{r}}\right)$, surface coverage $(\theta)$ and inhibition efficiency $(\eta \%)$ were determined using equations 1-3 [42-45]:

$$
\begin{aligned}
& C_{r}=\frac{w_{o}-w_{i}}{A t} \\
& \theta=\frac{w_{o}-w_{i}}{w_{o}} \\
& \eta \%=\frac{w_{o}-w_{i}}{w_{o}} \times 100
\end{aligned}
$$

where, $w_{i}$ and $w_{o}$ are the weight loss values $(\mathrm{mg})$ in presence and absence of inhibitor, respectively. A is the total area of the specimen in $\mathrm{cm}^{2}$ and $\mathrm{t}$ is the immersion time in minutes.

\section{Potentiodynamic polarization measurements}

Potentiodynamic polarization measurements were conducted using VoltaLab-PGZ-301 Potentiostat (France). A conventional cylindrical glass cell of $250 \mathrm{~mL}$ with three electrodes was used. A platinum sheet of 2 $\mathrm{cm}^{2}$ area and saturated calomel electrode (SCE) were used as auxiliary and reference electrodes, respectively. The working electrode in form of disc cut from mild steel with an area of $0.8 \mathrm{~cm}^{2}$ was embedded with epoxy except the working surface. Potentiodynamic polarization curves were obtained by changing the potential automatically from -400 to $+400 \mathrm{mV}$ versus open circuit potential (OCP) with a scan rate of $2 \mathrm{mV} \mathrm{s}^{-1}$. The inhibition efficiency $(\eta \%)$ was calculated using equation 4 as follows [43]: 


$$
\eta \%=\frac{i_{\text {corr (uninh) }}-i_{\text {corr }(\text { inh })}}{i_{\text {corr }(\text { uninh })}} \times 100
$$

Where $\mathrm{i}_{\text {corr(uninh) }}$ and $\mathrm{i}_{\text {corr(inh) }}$ are the corrosion current density values without and with inhibitors.

Open circuit potential (OCP)

\section{Results and discussion}

Open circuit potential versus time profile of carbon steel in $1 \mathrm{M} \mathrm{H}_{2} \mathrm{SO}_{4}$ solution at $25{ }^{\circ} \mathrm{C}$ in the absence and in the presence of different concentrations of the tested inhibitors are shown (representatively for $\mathrm{P}_{8}$ ) in Figure 2. More negative potential is an indication for higher corrosion rate in acidic medium in OCP studies [46]. It is clear that at the first stage of the measurements, the corrosion potential starts at high negative values depending on the inhibitor concentration. Then, the potential shifts to more positive values until reaches almost a constant value called the open circuit potential, OCP. The blank solution (solution with no inhibitors) has the most negative OCP value than the inhibited solutions. Furthermore, increasing the inhibitor concentrations shifts the OCP to more positive values. So, the presence of higher concentrations of the inhibitors increases the corrosion potentials of the carbon steel than the uninhibited medium.

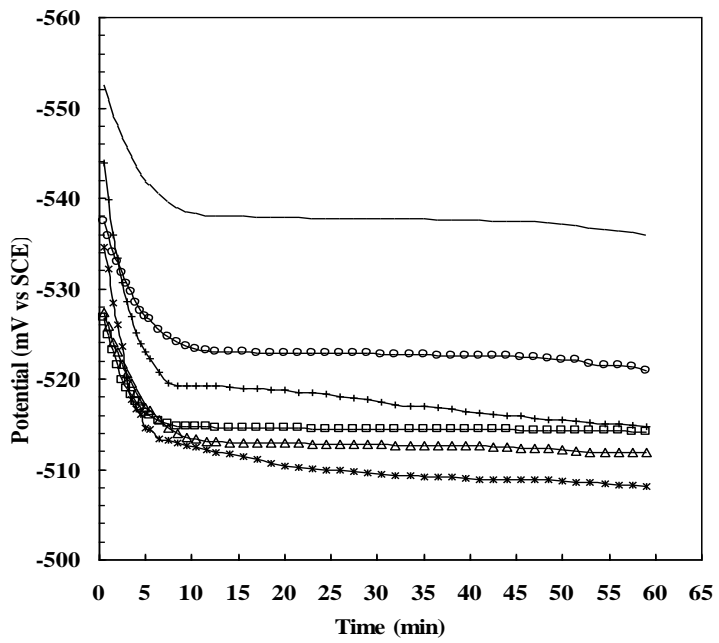

Figure 2: OCP vs. time of the carbon steel electrode immersed in $1 \mathrm{M} \mathrm{H}_{2} \mathrm{SO}_{4}$ solution in presence of different concentrations of $P_{8}$ inhibitor by weight $(*: 400$ ppm, $\Delta: 200$ ppm, $\square: 100$ ppm, +: 50 ppm, O: 25 ppm, —: blank) at $25^{\circ} \mathrm{C}$.

\section{Potentiodynamic polarization}

The effect of $\mathrm{P}_{8}, \mathrm{P}_{10}$ and $\mathrm{P}_{12}$ inhibitors on the corrosion of carbon steel was studied electrochemically using potentiodynamic measurements. Figure 3 shows typical polarization curves of carbon steel in $1 \mathrm{M} \mathrm{H}_{2} \mathrm{SO}_{4}$ solution in the absence and the presence of different concentrations of $\mathrm{P}_{8}$ inhibitor as representative for the tested inhibitors $\left(\mathrm{P}_{8}, \mathrm{P}_{10}\right.$ and $\left.\mathrm{P}_{12}\right)$. It is apparent from the polarization profile that both anodic and cathodic corrosion reactions of carbon steel electrode were inhibited after the addition of the different inhibitors to the acidic solution. Furthermore, the inhibition becomes more noticeable by increasing the inhibitor concentration from $25 \mathrm{ppm}$ to $400 \mathrm{ppm}$ by weight. This behaviour indicates that the addition of the inhibitors lessens the anodic dissolution of iron and also retards the hydrogen ions reduction (hydrogen evolution) [47]. The cathodic current-potential curves (Figure 3) give rise to parallel lines indicating that the addition of $\mathrm{P}_{8}, \mathrm{P}_{10}$ and $\mathrm{P}_{12}$ inhibitors to the $1 \mathrm{M} \mathrm{H}_{2} \mathrm{SO}_{4}$ solution do not modify the hydrogen evolution mechanism and the reduction of $\mathrm{H}^{+}$ ions at the carbon steel surface takes place mainly through a charge transfer mechanism [48-50]. The cathodic current densities decrease dramatically by increasing the inhibitors concentrations which reveals that the addition of $\mathrm{P}_{8}, \mathrm{P}_{10}$ and $\mathrm{P}_{12}$ does not change the cathodic hydrogen evolution mechanism. In the initial stage of the anodic polarization, the corrosion current densities increased slowly and the anodic polarization was enhanced predominantly with the polarization potential shifting positively. That shows the adsorption rate is higher than the desorption rate of the inhibitor molecules on carbon steel surface, and the adsorption process controls the anodic reaction [51-52]. But, the increase in the anodic potential beyond a particular potential with regard to the reference solution is due to desorption of inhibitor molecules from the metal surface.The polarization behaviour shows similar appearance, which implies that, the inhibitor molecules are thoroughly adsorbed from the solution to the carbon steel surface and their inhibition effect is increased by increasing the concentration [53-54]. 


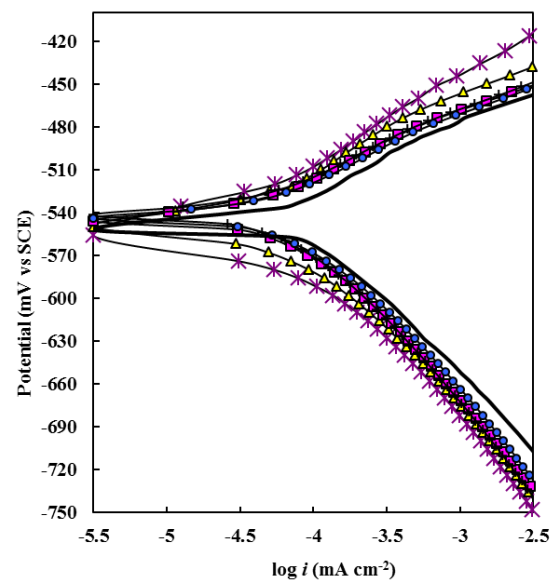

Figure 3: Polarization curve of carbon steel corrosion in $1 \mathrm{M} \mathrm{H}_{2} \mathrm{SO}_{4}$ in presence of different concentrations of $P_{8}$ inhibitor by weight $(*: 400 \mathrm{ppm}, \Delta: 200 \mathrm{ppm}, \square: 100 \mathrm{ppm},+: 50 \mathrm{ppm}, \mathrm{O}: 25 \mathrm{ppm}$, 一: blank) at $25^{\circ} \mathrm{C}$.

Table 1 collects the related corrosion electrochemical parameters, including corrosion potential $\left(\mathrm{E}_{\text {corr }}\right)$, corrosion current density $\left(\mathrm{i}_{\text {corr }}\right)$, cathodic and anodic Tafel slopes $\left(\beta_{\mathrm{c}}, \beta_{\mathrm{a}}\right)$, and inhibition efficiency $(\eta \%)$. It is evident that the increase of inhibitor concentration decreases the corrosion current densities and increases $\eta \%$, which suggests that the protective film adsorbed on the metal surface tends to be more complete at higher inhibitor concentrations. Furthermore, increasing the number of triethanolamine units in the inhibitors $(n=8,10$, 12) decreased the corrosion current density $\left(\mathrm{i}_{\text {corr }}\right)$ considerably. The inhibition efficiencies increased by increasing the polymerization extent in the following trend: $\mathrm{P}_{12}>\mathrm{P}_{10}>\mathrm{P}_{8}$. The inhibitor is classified as cathodic or anodic type if the displacement in corrosion potential is more than $85 \mathrm{mV}$ with respect to corrosion potential of the blank solution [53].

Table 1: Electrochemical parameters for the corrosion of carbon steel in $1 \mathrm{M} \mathrm{H}_{2} \mathrm{SO}_{4}$ solution containing different concentrations of $\mathbf{P}_{8}, \mathbf{P}_{10}$ and $P_{12}$ inhibitors at $25^{\circ} \mathrm{C}$

\begin{tabular}{|c|c|c|c|c|c|c|c|}
\hline Inhibitor & $\begin{array}{l}\text { Concentration, } \\
\text { ppm by weight }\end{array}$ & $\begin{array}{c}\mathbf{E}_{\text {corr }}, \\
(\mathrm{mV} \text { vs SCE) }\end{array}$ & $\begin{array}{c}\mathbf{i}_{\text {corr }} \\
\left(\mathrm{mA} \mathrm{cm}^{-2}\right) \\
\end{array}$ & $\begin{array}{c}\boldsymbol{\beta}_{\mathrm{a}} \\
\left(\mathrm{mV} \operatorname{dec}^{-1}\right) \\
\end{array}$ & $\begin{array}{c}\beta_{\mathrm{c}} \\
\left(\mathrm{mVV} \operatorname{dec}^{-1}\right) \\
\end{array}$ & $\theta$ & $\eta \%$ \\
\hline Blank & 0.0 & -580.3 & 0.323 & 88.2 & -142.6 & --- & --- \\
\hline \multirow{5}{*}{$\mathbf{P}_{8}$} & 25 & -565.6 & 0.075 & 63.1 & -131.4 & 0.76 & 76.4 \\
\hline & 50 & -539.9 & 0.072 & 60.8 & -135.1 & 0.78 & 77.8 \\
\hline & 100 & -542.9 & 0.067 & 60.3 & -130.2 & 0.79 & 79.4 \\
\hline & 200 & -541.8 & 0.061 & 61.1 & -132.7 & 0.81 & 81.1 \\
\hline & 400 & -553.3 & 0.056 & 58.2 & -132.9 & 0.83 & 82.6 \\
\hline \multirow{5}{*}{$\mathbf{P}_{10}$} & 25 & -544.9 & 0.074 & 57.7 & -130.3 & 0.77 & 77.0 \\
\hline & 50 & -536.5 & 0.068 & 53.3 & -131.0 & 0.79 & 79.0 \\
\hline & 100 & -537.2 & 0.061 & 55.0 & -139.9 & 0.81 & 81.3 \\
\hline & 200 & -533.4 & 0.052 & 57.8 & -141.7 & 0.84 & 84.1 \\
\hline & 400 & -536.8 & 0.039 & 51.3 & -129.7 & 0.88 & 87.8 \\
\hline \multirow{5}{*}{$\mathbf{P}_{12}$} & 25 & -544.5 & 0.055 & 61.5 & -144.6 & 0.83 & 83.0 \\
\hline & 50 & -538.2 & 0.043 & 58.1 & -141.4 & 0.86 & 86.3 \\
\hline & 100 & -534.3 & 0.039 & 50.4 & -139.1 & 0.87 & 87.1 \\
\hline & 200 & -542.0 & 0.036 & 48.3 & -136.0 & 0.89 & 89.4 \\
\hline & 400 & -550.8 & 0.034 & 50.6 & -146.0 & 0.92 & 91.6 \\
\hline
\end{tabular}

Data were average of three replicates with error ratio of $7 \%$

The presence of $\mathrm{P}_{12}, \mathrm{P}_{10}$, and $\mathrm{P}_{8}$ inhibitors resulted in slight shifts of corrosion potential compared to the potential obtained in the absence of inhibitor. However, the displacement of $E_{\text {corr }}$ is less than $85 \mathrm{mV}$ for all the studied inhibitors, but this displacement is not more than $43 \mathrm{mV}$. Therefore, these inhibitors can be classified as mixed-type inhibitors with a domain for anodic type inhibition [54-56]. Moreover, the values of the anodic and cathodic Tafel slopes $\left(\beta_{\mathrm{a}}, \beta_{\mathrm{c}}\right)$ showed no obvious changes with the addition of the inhibitors, which suggests that the inhibiting action of the inhibitors occurred by simple blocking of the available cathodic sites on the metal surface, which lead to a decrease in the exposed area necessary for hydrogen evolution and lowered the dissolution rate with increasing $\mathrm{P}_{8}, \mathrm{P}_{10}$, and $\mathrm{P}_{12}$ inhibitor concentration [57-59]. The surface coverage values showed an increasing trend by increasing the inhibitor concentration from $25 \mathrm{ppm}$ to $400 \mathrm{ppm}$ by weight, Table 
1. That shows a continuous increase of the adsorbed inhibitor molecules on the metal surface, which increases the inhibition efficiencies of the inhibitors. Increasing the inhibition efficiencies accompanied by increasing the inhibitors concentration can be attributed to the increase of the adsorbed layer thickness [60]. The inhibitors showed inhibition efficiencies in the following order: $\mathrm{P}_{12}>\mathrm{P}_{10}>\mathrm{P}_{8}$, respectively.

\section{Gravimetric measurements}

The data obtained from the gravimetric measurements were: corrosion rate $\left(C_{r}\right)$, surface coverage $(\theta)$ and inhibition efficiency $(\eta \%)$. The measurements were obtained at different immersion periods of $1,3,6$ and 24 hours and in the presence of 25, 50, 100, 200 and $400 \mathrm{ppm}$ by weight of $\mathrm{P}_{8}, \mathrm{P}_{10}$ and $\mathrm{P}_{12}$ inhibitors at $25{ }^{\circ} \mathrm{C}$.

\section{Effect of inhibitors concentration}

It is clear from data in Figure 4a-d that the increase of the inhibitors concentrations from 25 ppm to 400 ppm by weight decreased the corrosion rates of the carbon steel in $1 \mathrm{M} \mathrm{H}_{2} \mathrm{SO}_{4}$ solution. At a constant immersion time, the highest corrosion rates were obtained in the presence of $25 \mathrm{ppm}$ by weight for all the used inhibitors at all immersion times.

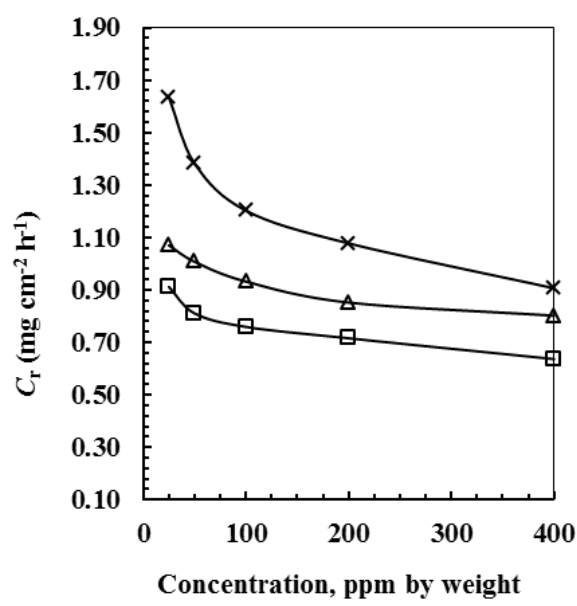

(a)

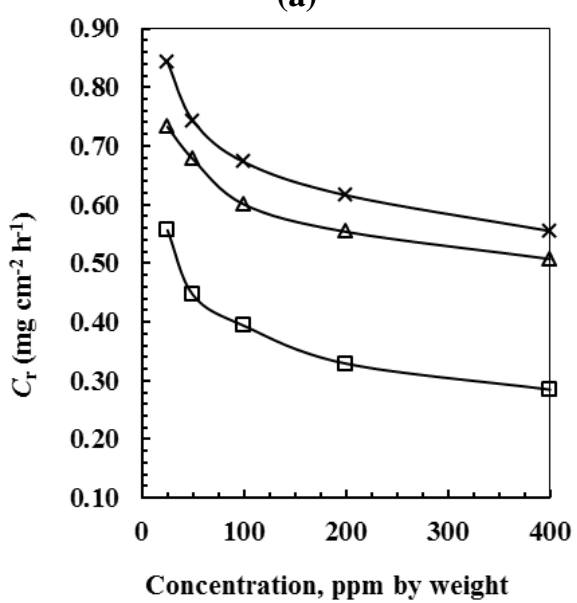

(c)

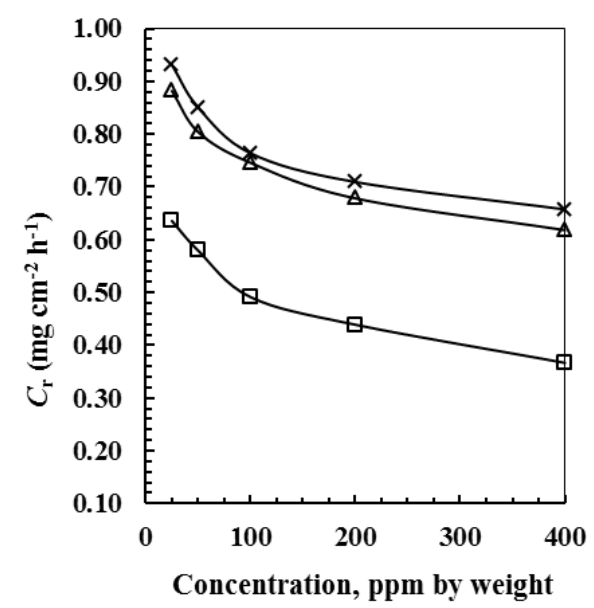

(b)

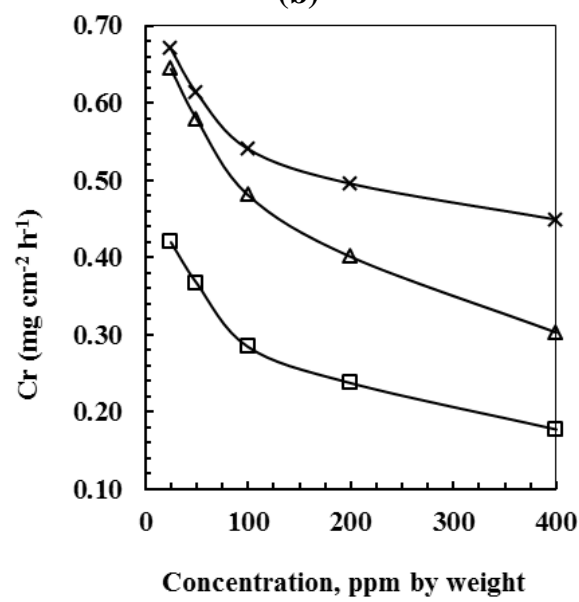

(d)

Figure 4: Effect of inhibitor concentration (ppm by weight) on the corrosion rate of the carbon steel in 1 $\mathrm{M} \mathrm{H}_{2} \mathrm{SO}_{4}$ in the presence of: $* \mathbf{P}_{8}, \Delta \mathbf{P}_{10}, \boxminus \mathbf{P}_{12}$ inhibitors after: (a) $1 \mathrm{~h}$, (b) $3 \mathrm{~h}$, (c) $6 \mathrm{~h}$, (d) $24 \mathrm{~h}$, at $25^{\circ} \mathrm{C}$.

The gradual increase of the inhibitors concentration from $25 \mathrm{ppm}$ to $400 \mathrm{ppm}$ by weight decreased the corrosion rates from 1.64 to $0.91,1.07$ to 0.80 and 0.91 to $0.64 \mathrm{mg} \cdot \mathrm{cm}^{-2} \cdot \mathrm{h}^{-1}$ for $\mathrm{P}_{8}, \mathrm{P}_{10}$ and $\mathrm{P}_{12}$ after 1 hour immersion, respectively at $25{ }^{\circ} \mathrm{C}$. The gradual decrease of the corrosion rates indicates the decrease of the carbon steel dissolution in the acidic medium. The decrease of corrosion rates by the increase of inhibitors concentration is an indication for the continuous accumulation of the inhibitor molecules on the metal surface. The adsorbed inhibitor molecules form a protective layer on the metal surface, which prevents the contact between the corrosive ions and the metal surface, and consequently decreases the corrosion extent. The increase of the inhibitor concentration increases the amount of adsorbed molecules at the metal surface, which can be 
expressed in term of the surface coverage $(\theta)$. The calculated surface coverage (equation 2) revealed that the increase of the inhibitors concentration from $25 \mathrm{ppm}$ to $400 \mathrm{ppm}$ by weight increased the surface coverage considerably. The increase of the surface coverage reached its maximum values for $\mathrm{P}_{8}, \mathrm{P}_{10}$ and $\mathrm{P}_{12}$ at $0.79,0.82$ and 0.86 after 1 hour immersion, and $0.87,0.91$ and 0.95 after 24 hour immersion in the presence of $400 \mathrm{ppm}$ by weight. The increase of the inhibitor concentration increased the inhibition efficiencies of the different inhibitors to reach the maximum at $400 \mathrm{ppm}$ by weight, Table 2 .

Table 2: Surface coverage $(\theta)$ and inhibition efficiency $(\eta \%)$ of the synthesized inhibitors $\left(\mathbf{P}_{\mathbf{8}}, \mathbf{P}_{10}\right.$ and $\left.\mathbf{P}_{12}\right)$ at different concentrations and different immersion time at $25^{\circ} \mathrm{C}$

\begin{tabular}{|c|c|c|c|c|c|c|c|c|c|}
\hline \multirow{3}{*}{ Inhibitors } & \multirow{3}{*}{$\begin{array}{c}\text { Inhibitor concentration, } \\
\text { ppm by weight }\end{array}$} & \multicolumn{8}{|c|}{ Immersion time, hours } \\
\hline & & \multicolumn{2}{|c|}{$1 \mathrm{~h}$} & \multicolumn{2}{|c|}{$3 \mathbf{h}$} & \multicolumn{2}{|c|}{$6 \mathrm{~h}$} & \multicolumn{2}{|c|}{$24 \mathrm{~h}$} \\
\hline & & $\theta$ & $\eta \%$ & $\theta$ & $\eta \%$ & $\theta$ & $\eta \%$ & $\theta$ & $\eta \%$ \\
\hline \multirow[t]{5}{*}{$\mathbf{P}_{8}$} & 400 & 0.79 & 79.4 & 0.82 & 82.3 & 0.85 & 84.9 & 0.87 & 86.5 \\
\hline & 200 & 0.76 & 75.5 & 0.81 & 80.9 & 0.83 & 83.3 & 0.85 & 85.1 \\
\hline & 100 & 0.73 & 72.7 & 0.79 & 79.5 & 0.82 & 81.7 & 0.84 & 83.8 \\
\hline & 50 & 0.69 & 68.6 & 0.77 & 77.1 & 0.80 & 79.8 & 0.82 & 81.6 \\
\hline & 25 & 0.63 & 62.8 & 0.75 & 75.0 & 0.77 & 77.1 & 0.80 & 79.9 \\
\hline \multirow[t]{5}{*}{$\mathbf{P}_{10}$} & 400 & 0.82 & 81.8 & 0.83 & 83.4 & 0.86 & 86.2 & 0.91 & 90.9 \\
\hline & 200 & 0.81 & 80.6 & 0.82 & 81.8 & 0.85 & 85.0 & 0.88 & 88.0 \\
\hline & 100 & 0.79 & 78.8 & 0.80 & 80.0 & 0.84 & 83.7 & 0.86 & 85.6 \\
\hline & 50 & 0.77 & 77.1 & 0.78 & 78.4 & 0.82 & 81.6 & 0.83 & 82.6 \\
\hline & 25 & 0.76 & 75.7 & 0.76 & 76.3 & 0.80 & 80.1 & 0.81 & 80.7 \\
\hline \multirow[t]{5}{*}{$\overline{\mathbf{P}_{12}}$} & 400 & 0.86 & 85.5 & 0.90 & 90.1 & 0.92 & 92.3 & 0.95 & 94.7 \\
\hline & 200 & 0.84 & 83.7 & 0.88 & 88.2 & 0.91 & 91.1 & 0.93 & 92.9 \\
\hline & 100 & 0.83 & 82.7 & 0.87 & 86.8 & 0.89 & 89.3 & 0.91 & 91.5 \\
\hline & 50 & 0.82 & 81.6 & 0.84 & 84.4 & 0.88 & 87.9 & 0.89 & 89.0 \\
\hline & 25 & 0.79 & 79.3 & 0.83 & 82.9 & 0.85 & 84.9 & 0.87 & 87.4 \\
\hline
\end{tabular}

Data were average of three replicates with error ratio of $7 \%$

The increase of the concentration increased the adsorbed inhibitor molecules on the metal surface, which is accompanied by a depression in the corrosion rates and an increase in the surface coverage. The adsorption of the inhibitor molecules on the metal surface is due to their surface activity. The surface activity of the inhibitor molecules is attributed to their amphipathic structure. The amphipathic structure is originated from the combination of hydrophilic groups (polar or charged groups) and hydrophobic groups in the inhibitor molecules. This combination increased the adsorption of the inhibitor molecules at the metal-solution interface by increasing their concentration [61].

\section{Effect of immersion time}

The influence of immersion time on the corrosion rate of carbon steel in the presence of the different inhibitors at different concentrations is represented in Figure 5a-c. The corrosion rates of the carbon steel in the absence of the inhibitors at 1, 3, 6 and 24 hours were: $4.40,3.83,3.76$ and $3.33 \mathrm{mg} \mathrm{cm}^{-2} \mathrm{~h}^{-1}$ at $25^{\circ} \mathrm{C}$. At constant inhibitor concentration, the corrosion rate decreased by increasing the immersion time. That was attributed to the increase of the adsorbed amount of the inhibitor molecules on the metal surface. That increased the performance of the protective layer formed in the protection of the metal surface against the corrosion reaction $[61,62]$. The results obtained from weight loss measurements for both the protected and unprotected carbon steel samples showed good efficiencies for the tested inhibitors after 24 hours as indicated in Figure 5a-c.

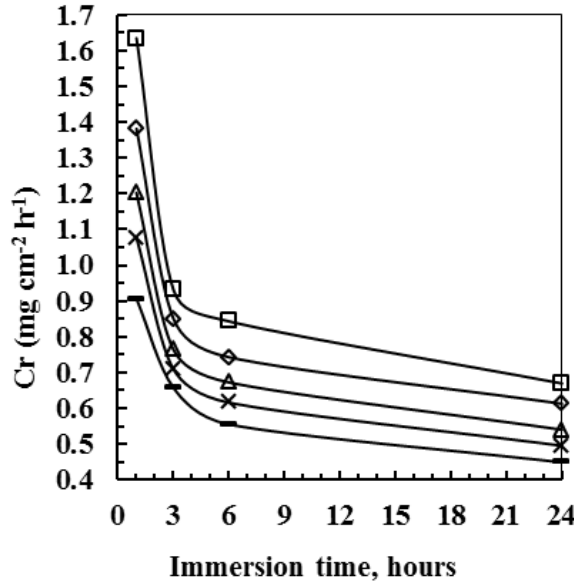

(a)

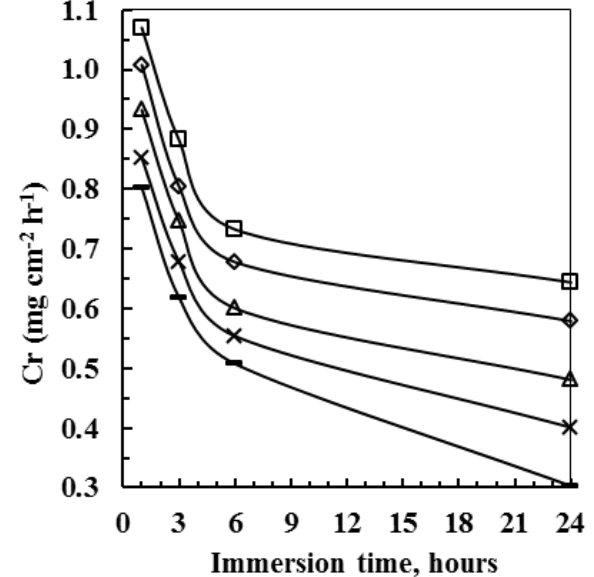

(b) 


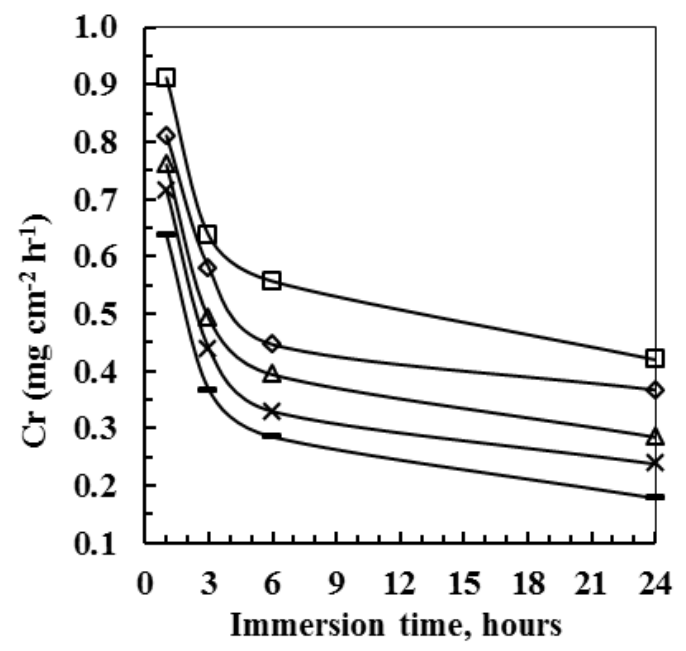

(c)

Figure 5: Effect of immersion time on the corrosion rate of carbon steel in $1 \mathrm{M} \mathrm{H}_{2} \mathrm{SO}_{4}$ in the presence of: $\square 25$ ppm, $\diamond 50$ ppm, $\Delta 100$ ppm, $\times 200$ ppm, - 400 ppm (by weight) of (a) $P_{8}$, (b) $P_{10}$, (c) $P_{12}$ inhibitors at $25^{\circ} \mathrm{C}$.

\section{Adsorption isotherm}

The adsorption behaviour of the inhibitor molecules on metal surface is useful in explaining their inhibition mechanism [63,64]. The Langmuir adsorption isotherm was found to be the best description of the adsorption behaviour of the inhibitor on carbon steel surface, which obeys Equation (5) $[65,66]$.

$$
\frac{C_{i}}{\theta}=\frac{1}{K_{a d s}}+C_{i}
$$
overage.

Where $C_{i}$ is the inhibitor concentration, $K_{a d s}$ is the adsorption equilibrium constant and $\theta$ is surface

The surface coverage $(\theta)$ for different concentrations of inhibitor in $\mathrm{H}_{2} \mathrm{SO}_{4}$ solution was obtained from weight loss results and listed in Table 2. The linear relationship of $C_{i} / \theta$ versus $C_{i}$ displayed in Figure 6 show that the adsorption of $\mathrm{P}_{8}, \mathrm{P}_{10}$ and $\mathrm{P}_{12}$ on carbon steel surface is well fitted by the Langmuir adsorption isotherm (the slope is close to 1 and correlation coefficient $\left(R^{2}\right)$ is close to 1 ). The intercept of $C_{i} / \theta$ versus $C_{i}$ line is used to calculate the adsorption equilibrium constant.

Adsorption equilibrium constant $\left(\mathrm{K}_{\mathrm{ads}}\right)$ is correlated to the standard free energy of adsorption $\left(\Delta \mathrm{G}^{\circ}{ }_{\text {ads }}\right)$ of the inhibitor molecules on the metal surface according to equation (6) [67]:

$$
K_{a d s}=\frac{1}{55.5} e^{\frac{-\Delta G_{a d s}^{\circ}}{R T}}
$$

Generally, $\Delta \mathrm{G}^{\circ}$ ads values of $-20 \mathrm{~kJ} \mathrm{~mol}^{-1}$ or less negative are associated with an electrostatic interaction between charged molecules and charged metal surface, i.e., physisorption [68]. While, those of $-40 \mathrm{~kJ} \mathrm{~mol}^{-1} \mathrm{or}^{-}$ more negative regarded as chemisorption, which is formed by sharing or transferring of charges from the inhibitor molecules on the metal surface to form a covalent bonds [69]. $\Delta G_{a d s}^{o}$ values of the studied inhibitors ranged between $-36.42 \mathrm{~kJ} \mathrm{~mol}^{-1}$ and $-38.74 \mathrm{~kJ} \mathrm{~mol}^{-1}$, Table 3. These values are indicate that the inhibitors adsorbed on the metal surface via mixed mechanism; involved physical and chemical adsorption. Physical adsorption occurred between the active positive centres on the metal surface and the lone electron pair of the nitrogen atoms. Chemical adsorption occurred by forming coordination bonds between the inhibitor molecules and the d-orbital of $\mathrm{Fe}$ on the steel surface through lone pair of electron of $\mathrm{O}$ and $\mathrm{N}$ atoms [70-72]. Increasing the number of triethanol amine units and alkyl chains from oleic acid moieties in the inhibitors increased the negativity of $\Delta G_{a d s}^{o}$ values, which can be attributed to the role of the triethanol amine and oleic acid moieties in the adsorption on the carbon steel- $\mathrm{H}_{2} \mathrm{SO}_{4}$ solution interface $[61,67]$. 
Table 3: Adsorption constant and free energy of adsorption of $P_{8}, P_{10}$ and $P_{12}$ inhibitors on the carbon steel surface in $1 \mathrm{M} \mathrm{H}_{2} \mathrm{SO}_{4}$ at $25^{\circ} \mathrm{C}$

\begin{tabular}{|c|c|c|c|}
\hline Inhibitor & $\mathbf{R}^{2}$ & $K_{\text {ads }}\left(M^{-1} \mathbf{x} 10^{5}\right)$ & $\Delta \mathbf{G}_{\text {ads }}^{0}, \mathrm{~kJ} \mathrm{~mol}^{-1}$ \\
\hline $\mathbf{P}_{8}$ & 1 & 4.3 & $-35.42 \pm 2.48$ \\
\hline $\mathbf{P}_{10}$ & 0.9998 & 5.0 & $-37.46 \pm 2.62$ \\
\hline $\mathbf{P}_{12}$ & 0.9999 & 11.1 & $-39.74 \pm 2.78$ \\
\hline
\end{tabular}

Data were average of three replicates with error ratio of $7 \%, \mathrm{SD}=1$

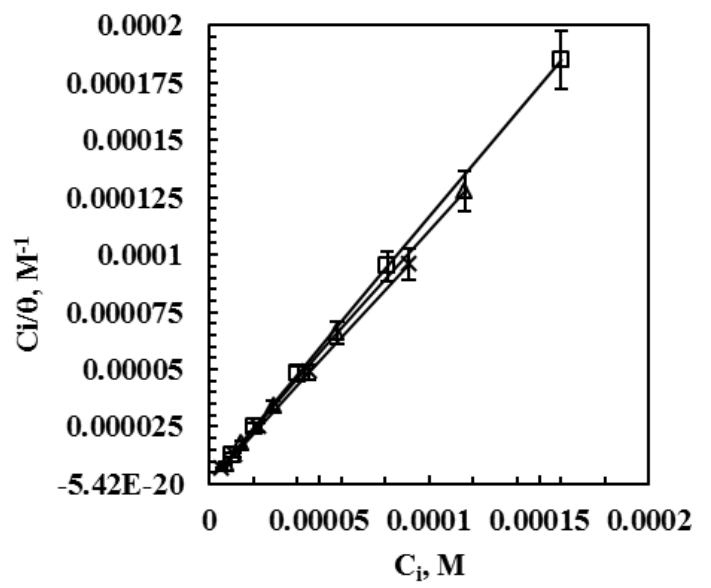

Figure 6: Langmuir adsorption isotherm of $P_{8}, P_{10}$ and $P_{12}$ inhibitors on carbon steel at $25{ }^{\circ} \mathrm{C}$, error $\%=$ $7, \mathrm{SD}=1$.

\section{Mechanism of corrosion inhibition}

Electrochemical and weight loss methods were employed to study the behaviour of carbon steel corrosion in $1 \mathrm{M} \mathrm{H}_{2} \mathrm{SO}_{4}$, in the presence of $\mathrm{P}_{8}, \mathrm{P}_{10}$ and $\mathrm{P}_{12}$ inhibitors. The inhibition efficiency is increased by the increasing of inhibitor concentrations, which indicated a gradual increase of the surface coverage of the different inhibitors on the metal surface. The first stage of the inhibition mechanism is the adsorption of inhibitors on the metal surface [61]. In most inhibition studies, the formation of donor-acceptor surface complexes between $\pi$-electrons of inhibitor and the vacant d-orbital of metal were assumed [73]. $\mathrm{P}_{8-12}$ inhibitors contain several donating groups including: hydroxyl groups $(\mathrm{OH})$, ether linkage $(-\mathrm{O}-)$ and double bonds $(\mathrm{C}=\mathrm{C})$ of oleic acid moiety. These groups acted as electron donating groups, which donate their lone pair of electrons to the vacant d-orbitals of Fe. In addition, the inhibitors transformed from the neutral to the cationic forms in the acidic medium [74]. That makes the inhibitor molecules adsorb on $\mathrm{Fe}$ surface by electrostatic interaction between the negatively charged centres on Fe surface and the positively charged nitrogen atoms $\left(\mathrm{N}^{+}\right)$[75-78]. Therefore, $\mathrm{P}_{8}, \mathrm{P}_{10}$ and $\mathrm{P}_{12}$ inhibitors exhibit high efficiency in $\mathrm{H}_{2} \mathrm{SO}_{4}$. In addition, larger molecular area of $\mathrm{P}_{8}$, $\mathrm{P}_{10}$ and $\mathrm{P}_{12}$ inhibitors [41] played an important role in retarding the corrosion by covering the wide area on the metal surface. The area of the inhibitors at the interface is increased by increasing the degree of polymerization of triethanolamine from 8 units to 12 units per molecule. That was accompanied by gradual increasing in their corrosion inhibition efficiency.

\section{Surface activity-corrosion inhibition relationship}

The surface activity of the synthesized inhibitors were measured based on the surface tension values and critical micelle concentrations (CMC). The relationship between the surface tension and $-\log \mathrm{C}$ of the synthesized inhibitors is plotted in Figure 7 as representative for the synthesized inhibitors at $25{ }^{\circ} \mathrm{C}$. Two conclusions can be obtained from Figure 7. First, the gradual increase in the inhibitor concentration of decreases the surface tension values considerably. Second, within the homologue series of $\mathrm{P}_{8}, \mathrm{P}_{10}$, and $\mathrm{P}_{12}$, increasing the number of the polyethylene glycol oleate chains attached to the polymer chain decreases the surface tension values. Increasing the number of polyethylene glycol oleate chains in the inhibitor molecule increases their hydrophobic characters which increases their tendency to adsorb at the air/water interface, which decreases their surface tension considerably.

The critical micelle concentration values (CMC) of these surfactants were determined by the intercept of the pre- and post-micellar regions in Figure 7. These values are listed in Table 4. Generally, CMC values depend on the number of polyethylene glycol oleate chains attached to the different molecules and the number of the triethanolamine molecules polymerized in the inhibitor molecules. The gradual increase of the polyethylene glycol oleate chain numbers from two to four in the inhibitor molecules decreases CMC values 
considerably from 2.51 to $0.06 \mathrm{mM}$. Also, that behavior is predominant in $\mathrm{P}_{10}$ and $\mathrm{P}_{12}$ series due to the increase of the hydrophobic characteristics of the molecules. The same behavior was observed by increasing the triethanolamine units in the surfactant molecules and this was in good agreement with the previous study [79]. The increase of the polymerized units from eight to ten units decreases the values of CMC values by a factor of 0.1 . Also the $\mathrm{CMC}$ value of $\mathrm{P}_{12}$ is decreased by a factor of 0.1 more than $\mathrm{P}_{10}$ derivatives, Table 4 .

That is expected from the increase in hydrophobicity of the molecules as the number of methylene groups increases by increasing the degree of polymerization [80-81]. This decrease is linear as is seen in Figure 7. This usually happens in a homologous series of anionic [82], cationic [83-84] and nonionic [85] surfactants.

The relation between the surface activity and $\eta \%$ was established in a previous work [86]. Increasing the number of hydrophobic chains in the inhibitor molecules increases their surface activity and the tendency towards adsorption at the interfaces [87] as represented from HLB values. Moreover, increasing the adsorption tendency increases the amounts of adsorbed molecules on the metal surface, which consequently increase the surface coverage values $(\theta)$, (Table 2). As a result, the metal surface is protected from the dissolution as the action of the acid solution.

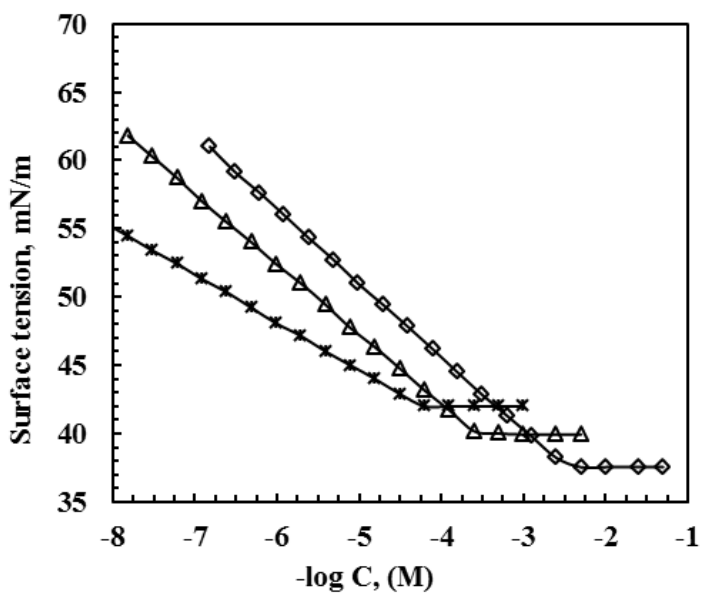

Figure 7: Surface tension vs. $-\log$ (concentration) profile of: $\diamond: P_{8} ; \Delta: P_{10} ; *: P_{12}$ inhibitors at $25^{\circ} \mathrm{C}$.

Table 4: Surface parameters of the tested inhibitors at $25^{\circ} \mathrm{C}$

\begin{tabular}{ccc} 
Surfactants & CMC, $\mathbf{m M}$ & HLB \\
\hline $\mathbf{P}_{\mathbf{8}}$ & 2.51 & 7.1 \\
\hline $\mathbf{P}_{\mathbf{1 0}}$ & 0.20 & 7.7 \\
\hline $\mathbf{P}_{\mathbf{1 2}}$ & 0.06 & 8.0 \\
\hline
\end{tabular}

\section{Conclusions}

(1) The synthesized inhibitors $\mathrm{P}_{8}, \mathrm{P}_{10}$ and $\mathrm{P}_{12}$ act as efficient inhibitor for the corrosion of carbon steel in $1 \mathrm{M}$ $\mathrm{H}_{2} \mathrm{SO}_{4}$. Inhibition efficiency ( $\left.\eta \%\right)$ increased by increasing the inhibitors concentration; and the maximum $\eta \%$ values at $400 \mathrm{ppm}$ by weight are $86.5 \%-94.7 \%$ at $25^{\circ} \mathrm{C}$.

(2) The adsorption of the different inhibitors on carbon steel surface obeyed Langmuir adsorption isotherm.

(3) The inhibitors act as mixed-type inhibitor with a domain of anodic type properties in $1 \mathrm{M} \mathrm{H}_{2} \mathrm{SO}_{4}$, and their inhibition on carbon steel proceeded by physical adsorption (physisorption).

(4) Increasing the triethanol amine units and the critical micelle concentrations of the inhibitors increased the inhibition efficiency of the different inhibitors.

\section{References}

[1] G.L. Scattergood, Corrosion Inhibitors for Crude Oil Refineries, Corrosion, ASM Handbook, vol. 13, ASM International, 1992.

[2] M.A. Amin, S.S. Abd El-Rehim, E.E.F. El-Sherbini, R.S. Bayoumi, The inhibition of low carbon steel corrosion in hydrochloric acid solutions by succinic acid: part I weight loss, polarization, EIS, PZC, EDX and SEM studies, Electrochim. Acta 52 (2007) 3588-3600.

[3] Y. Abboud, A. Abourriche, T. Saffaj, M. Berrada, M. Charrouf, A. Bennamara, H. Hannache, A novel azo dye, 8-quinolinol-5azoantipyrine as corrosion inhibitor for mild steel in acidic media, Desalination 237 (2009) 175-189.

[4] X. Liu, P.C. Okafor, Y.G. Zheng, The inhibition of $\mathrm{CO}_{2}$ corrosion of $\mathrm{N} 80$ mild steel in single liquid phase and liquid/particle twophase flow by aminoethyl imidazoline derivatives, Corros. Sci. 51 (2009) 744-751.

[5] X. Li, S. Deng, H. Fu, Synergism between red tetrazolium and uracil on the corrosion of cold rolled steel in $\mathrm{H}_{2} \mathrm{SO}_{4}$ solution, Corros. Sci. 51 (2009) 1344-1355. 
[6] F.G. Liu, M. Du, J. Zhang, M. Qiu, Electrochemical behavior of Q235 steel in saltwater saturated with carbon dioxide based on new imidazoline derivative inhibitor, Corros. Sci. 51 (2009) 102-109.

[7] M. Finšgar, S. Fassbender, F. Nicolini, I. Milošev, Polyethyleneimine as a corrosion inhibitor for ASTM 420 stainless steel in nearneutral saline media, Corros. Sci. 51 (2009) 525-533.

[8] Q. Qu, Z. Hao, L. Li, W. Bai, Y. Liu, Z. Ding, Synthesis and evaluation of trihydroxymethyl-(2-hydroxybenzylidenamino)methane as a corrosion inhibitor for cold rolled steel in hydrochloric acid, Corros. Sci. 51 (2009) 569-574.

[9] F. Bentiss, M. Traisnel, M. Lagrenee, The substituted 1,3,4-oxadiazoles: a new class of corrosion inhibitors of mild steel in acidic media, Corros. Sci. 42 (2000) 127-146.

[10] F. Touhami, A. Aouniti, S. Kertit, Y. Abed, B. Hammouti, A. Ramdani, K. Elkacemi, Corrosion inhibition of armco iron in 1 M $\mathrm{HCl}$ media by new bipyrazolic derivatives, Corros. Sci. 42 (2000) 929-940.

[11] S.Y. Shiao, V. Chhabra, A. Patist, M.L. Free, P.D.T. Huibers, A. Gregory, S. Patel, D.O. Shah, Chain length compatibility effects in mixed surfactant systems for technological applications, Adv. Colloid Int. Sci. 74 (1998) 1-29.

[12] S.A. Umoren, O. Ogbobe, I.O. Igwe, E.E. Ebenso, Inhibition of mild steel corrosion in acidic medium using synthetic and naturally occurring polymers and synergistic halide additives, Corros. Sci. 50 (2008) 1998-2006.

[13] M.L. Free, Understanding the effect of surfactant aggregation on corrosion inhibition of mild steel in acidic medium, Corros. Sci. 44 (2002) 2865-2870.

[14] L. Niu, H. Zhang, F. Wei, S. We, X. Cao, P. Liu, Corrosion inhibition of iron in acidic solution by alkyl quaternary ammonium halides, Appl. Surf. Sci. 252 (2005) 1634-1642.

[15] W.L. Wang, M.L. Free, Prediction and measurement of corrosion inhibition of mild steel using nonionic surfactants in chloride media, Corros. Sci. 46 (2004) 2601-2611.

[16] L.G. Qiu, Y. Wu, Y.M. Wang, X. Jiang, Synergistic effect between cationic gemini surfactant and chloride ion for the corrosion inhibition of steel in sulphuric acid, Corros. Sci. 50 (2008) 576-582.

[17] M.L. Free, A new corrosion inhibition model for surfactants that more closely accounts for actual adsorption than traditional models that assume physical coverage is proportional to inhibition, Corros. Sci. 46 (2004) 3101-3113.

[18] S.S. Abd El Rehim, H.H. Hassan, M.A. Amin, Corrosion inhibition study of pure $\mathrm{Al}$ and some of its alloys in $1 \mathrm{M}$ HCl solution by impedance technique, Corros. Sci. 46 (2004) 5-25.

[19] L.G. Qiu, A.J. Xie, Y.H. Shen, Understanding the adsorption of cationic Gemini surfactants on steel surface in hydrochloric acid, Mat. Chem. Phys. 87 (2004) 237-240.

[20] X. Li, S. Deng, G. Mu, H. Fu, F. Yang, Inhibition effect of nonionic surfactant on the corrosion of cold rolled steel in hydrochloric acid, Corros. Sci. 50 (2008) 420-430.

[21] R. Guo, T. Liu, X. Wei, Effect of SDS and alcohols on the inhibition efficiency of corrosion of nickel, Colloid. Surf. A 209 (2002) $37-45$.

[22] S.T. Keera, M.A. Deyab, Effect of some organic surfactants on the electrochemical behavior of carbon steel in formation water, Colloid. Surf. A 266 (2005) 129-140.

[23] T.Y. Soror, M.A. El-Ziady, Effect of cetyl trimethyl ammonium bromide on the corrosion of carbon steel in acids, Mat. Chem. Phys. 77 (2002) 697-703.

[24] H. Ma, S. Chen, B. Yin, S. Zhao, X. Liu, Impedance spectroscopic study of corrosion inhibition of copper by surfactants in the acidic solutions, Corros. Sci. 45 (2003) 867-882.

[25] A. Meziani, D. Touraud, M. Clausse, W. Kunz, Co-surfactant properties of ketones, J. Mol. Liquids 84 (2000) $301-311$.

[26] Q. Yang, Q. Zhou, P. Somasundaran, NMR study of micellar microstructures of cationic single-chain and gemini surfactants and their mixtures with nonionic surfactant N-dodecyl-b-D-maltoside, Colloid. Surf. A 322 (2008) 40-46.

[27] G.B. Ray, I. Chakraborty, S. Ghosh, S.P. Moulik, On mixed binary surfactant systems comprising MEGA-10 and alkyl trimethyl ammonium bromides: a detailed physicochemical study with a critical analysis, J. Colloid. Int. Sci. 307 (2007) $543-553$.

[28] G.X. Zhao, B.Y. Zhu, Z.P. Dou, P. Yan, J.X. Xiao, Effect of charge distribution along surfactant molecules on physicochemical properties of surfactant systems, Colloid. Surf. A 327 (2008) 122-126.

[29] A. Tizpar, Z. Ghasemi, The corrosion inhibition and gas evolution studies of some surfactants and citric acid on lead alloy in 12.5 $\mathrm{M} \mathrm{H}_{2} \mathrm{SO}_{4}$ solution, Appl. Surf. Sci. 252 (2006) 8630-8634.

[30] R. Fuchs-Godec, Effect of the nature of the counter ions of N-alkyl quaternary ammonium salts on inhibition of the corrosion process, ActaChim. Slov. 54 (2007) 492-502.

[31] R. Fuchs-Godec, Inhibitory effect of non-ionic surfactants of the TRITON-X series on the corrosion of carbon steel in sulphuric acid, Electrochim. Acta. 52 (2007) 4974-4981.

[32] R. Fuchs-Godec, Effects of surfactants and their mixtures on inhibition of the corrosion process of ferritic stainless steel, Electrochim. Acta. 54 (2009) 2171-2179.

[33] R. Fuchs-Godec, The erosion-corrosion inhibition of AISI 431 stainless steel in $2.0 \mathrm{M} \mathrm{H}_{2} \mathrm{SO}_{4}$ solution using N-alkyl quaternary ammonium salts as inhibitors, Ind. Eng. Chem. Res. 49 (2010) 6407-6415.

[34] N.A. Negm, F.M. Zaki, Corrosion inhibition efficiency of nonionic Schiff base amphiphiles of p-aminobenzoic acid for aluminum in 4N HCl, Colloids Surf. A. 322 (2008) 97-102.

[35] X. Li, S. Deng, G. Mu, H. Fu, F. Yang, Inhibition effect of nonionic surfactant on the corrosion of cold rolled steel in hydrochloric acid, Corros. Sci. 50 (2008) 420-430.

[36] M.A. Hegazy, M.F. Zaky, Inhibition effect of novel nonionic surfactants on the corrosion of carbon steel in acidic medium, Corros. Sci. 52 (2010) 1333-1341.

[37] D. Asefi, N.M. Mahmoodi, M. Arami, Effect of nonionic co-surfactants on corrosion inhibition effect of cationic Gemini surfactant, Colloids Surf. A. 355 (2010) 183-186.

[38] D. Asefi, M. Arami, A.A. Sarabi, N.M. Mahmoodi, The chain length influence of cationic surfactant and role of nonionic cosurfactants on controlling the corrosion rate of steel in acidic media, Corros. Sci. 51 (2009) 1817-1821.

[39] Z. Huang, T. Gu, Mixed adsorption of nonionic and cationic surfactants on silica gel and methylated silica gel, Colloids Surf. 28 (1987) 159-168.

[40] M.M. Saleh, A.A. Atia, Effects of structure of the ionic head of cationic surfactant on its inhibition of acid corrosion of mild steel, J. Appl. Electrochem. 36 (2006) 899-905.

[41] N.A. Negm, A.F. El-Farargy, S.M. Tawfik, A.M. Abdelnour, H.H. Hefni, M.M. Khowdiary (2013) Synthesis, surface and thermodynamic properties of substituted polytriethanolamine nonionic surfactants, J. Surfact. Deterg. DOI 10.1007/s11743-0121412-6.

[42] J. Yu, F. Gan, L. Jiang, Inhibition effect of 2-amino-5-mercapto-1,2,4-triazole on copper corrosion, Corrosion 64 (2008) 900-904.

[43] ASTM G3-89, standard practice for conventions applicable to electrochemical measurements in corrosion testing (1994). 
[44] H.H. Hassan, Effect of chloride ions on the corrosion behaviour of steel in $0.1 \mathrm{M}$ citrate, Electrochim. Acta 51 (2005) 526-534.

[45] C.H. Hsu, F. Mansfeld, Atmospheric corrosion of B6 bronze evaluated by the thin layer activation technique, Corros. J. 57 (2001) $747-752$.

[46] N.A. Negm, A.M. Al Sabagh, M.A. Migahed, H.M. Abdel Bary and H.M. El Din, Effectiveness of some diquaternary ammonium surfactants as corrosion inhibitors for carbon steel in $0.5 \mathrm{M} \mathrm{HCl}$ solution, Corros. Sci. 52 (2010) 2122-2132.

[47] M. Lagrenee, B. Mernari, M. Bouanis, M. Traisnel, F. Bentiss, Study of the mechanism and inhibiting efficiency of 3,5-bis(4methylethiophenyl)-4H-1,2,4-triazole on mild steel corrosion in acidic media, Corros. Sci. 44 (2002) 573-588.

[48] R. Solmaz, G. Kardas, M.C. Ulha, B. Yazici, M. Erbil, Investigation of desorption and inhibitive effect of 2-mercaptothiazoline on corrosion of mild steel in hydrochloric acid media, Electrochim. Acta 53 (2008) 5941-5952.

[49] S.A. Umoren, O. Ogbobe, I.O. Igwe, E.E. Ebenso, Inhibition of mild steel corrosion in acidic medium using synthetic and naturally occurring polymers and synergistic halide additives, Corros. Sci. 50 (2008) 1998-2006.

[50] M. Lebrini, M. Lagrenée, H. Vezin, M. Traisnel, F. Bentiss, Experimental and theoretical study for corrosion inhibition of mild steel in normal hydrochloric acid solution by some new macrocyclic polyether compounds, Corros. Sci. 49 (2007) 2254-2269.

[51] Q. Qu, Z.Z. Hao, L. Li, W. Bai, Y.J. Liu, Z.T. Ding, Synthesis and evaluation of tri-hydroxymethyl-(2-hydroxybenzylidenamino)methane as a corrosion inhibitor for cold rolled steel in hydrochloric acid, Corros. Sci. 51 (2009) 569-574.

[52] Y. Yan, W. Li, L. Cai, B. Hou, Electrochemical and quantum chemical study of purines as corrosion inhibitors for mild steel in 1 M $\mathrm{HCl}$ solution, Electrochim. Acta 53 (2008) 5953-5961.

[53] N.A. Negm, F.M. Zaky, Corrosion inhibition efficiency of nonionic Schiff base amphiphiles of p-aminobenzoic acid for aluminum in $4 \mathrm{~N} \mathrm{HCl}$, Colloids Surf. A. 322 (2008) 97-102.

[54] V.V. Torres, R.S. Amado, C. Faia de Sá, T.L. Fernandez, C.A.S. Riehl, A.G. Torres, E. D’Elia, Inhibitory action of aqueous coffee ground extracts on the corrosion of carbon steel in $\mathrm{HCl}$ solution, Corros. Sci. 53 (2011) 2385-2392.

[55] N.A. Negm, F.M. Zaky, Corrosion inhibition efficiency of nonionic Schiff base amphiphiles of p-aminobenzoic acid for aluminum in $4 \mathrm{~N} \mathrm{HCl}$, Colloids Surf. A. 322 (2008) 97-102.

[56] O.K. Abiola, J.O.E. Otaigbe, The effects of Phyllanthusamarus extract on corrosion and kinetics of corrosion process of aluminum in alkaline solution, Corros. Sci. 51 (2009) 2790-2793.

[57] N.A. Negm, A.M. Al Sabagh, M.A. Migahed, H.M. Abdel-Bary, H.M. El Din, Effectiveness of some diquaternary ammonium surfactants as corrosion inhibitors for carbon steel in $0.5 \mathrm{M} \mathrm{HCl}$ solution, Corros. Sci. 52 (2010) 2122-2132.

[58] J.C. Rocha, J.A.C.P. Gomes, E. D’Elia, Corrosion inhibition of carbon steel in hydrochloric acid solution by fruit peel aqueous extracts, Corros. Sci. 52 (2010) 2341-2348.

[59] N.A. Negm, Y.M. Elkholy, S.M. Tawfik, Corrosion inhibition of carbon steel by some quaternary surface active isoxazol-2-ium cationic Schiff bases in hydrochloric acid solution, Corros. Sci. 53 (2011) 3566-3575.

[60] N.A. Negm E.A. Badr, I.A. Aiad, M.F. Zaki, M.M. Said, Investigation the inhibitory action of novel diquaternary Schiff dibases on the acid dissolution of carbon steel in 1 M hydrochloric acid solution, Corros. Sci. 65 (2012) 77-86.

[61] A. Popova, M. Christov, S. Raicheva, E. Sokolova, Adsorption and inhibitive properties of benzimidazole derivatives in acid mild steel corrosion, Corros. Sci. 46 (2004) 1333-1350.

[62] C. Kustu, K.C. Emregul, O. Atakol, Schiff bases of increasing complexity as mild steel corrosion inhibitors in 2 M HCl, Corros. Sci. 49 (2007) 2800-2814.

[63] N.A. Negm, N.G. Kandile, E.A. Badr, M.A. Mohammed, Gravimetric and electrochemical evaluation of environmentally friendly nonionic corrosion inhibitors for carbon steel in $1 \mathrm{M} \mathrm{HCl}$, Corros. Sci. 65 (2012) 94-103.

[64] V.R. Saliyan, A.V. Adhikari, Quinolin-5-ylmethylene-3-\{[8-(trifluoromethyl) quinolin-4-yl]thio\} propanohydrazide as an effective inhibitor of mild steel corrosion in $\mathrm{HCl}$ solution, Corros. Sci. 50 (2008) 55-61.

[65] C. Fiaud, A. Harch, D. Mallouh, M. Tzinmann, The inhibition of iron corrosion by acetylenic alcohols in acid solutions at high temperature, Corros. Sci. 35 (1993) 1437-1444.

[66] C. Kustu, K.C. Emregul, O. Atakol, Schiff bases of increasing complexity as mild steel corrosion inhibitors in 2 M HCl, Corros. Sci. 49 (2007) 2800-2814.

[67] A. Raman, P. Labine, Reviews on Corrosion Inhibitor Science and Technology, vol. 1.11, NACE, Houston, TX, 1986, p. 20.

[68] C.S. Hsu, F. Mansfeld, Concerning the conversion of the constant phase element parameter $\psi_{\mathrm{o}}$ into a capacitance, Corrosion 57 (2001) 747-748.

[69] X. Li, S. Deng, H. Fu, Allylthiourea as a corrosion inhibitor for cold rolled steel in $\mathrm{H}_{3} \mathrm{PO}_{4}$ solution, Corros. Sci. 55 (2012) $280-288$.

[70] S. Deng, X Li, Inhibition by Ginkgo leaves extract of the corrosion of steel in $\mathrm{HCl}_{\text {and }} \mathrm{H}_{2} \mathrm{SO}_{4}$ solutions, Corros. Sci. 55 (2012) $407-$ 415 .

[71] N. Soltani, M. Behpour, S.M. Ghoreishi, H. Naeimi, Corrosion inhibition of mild steel in hydrochloric acid solution by some double Schiff bases, Corros. Sci. 52 (2010) 1351-1361.

[72] S. Safak, B. Duran, A. Yurt, G. Turkoglu, Schiff bases as corrosion inhibitor for aluminium in HCl solution, Corros. Sci. 54 (2012) 251-259.

[73] A. Popova, M. Christov, A. Zwetanova, Effect of the molecular structure on the inhibitor properties of azoles on mild steel corrosion in $1 \mathrm{M}$ hydrochloric acid, Corros. Sci. 49 (2007) 2131-2143.

[74] K.F. Khaled, Application of electrochemical frequency modulation for monitoring corrosion and corrosion inhibition of iron by some indole derivatives in molar hydrochloric acid, Mater. Chem. Phys. 112 (2008) 290-300.

[75] A. Asan, M. Kabasakaloglu, M. Isiklan, Z. Kilic, Corrosion inhibition of brass in presence of terdentate ligands in chloride solution, Corros. Sci. 47 (2005) 1534-1544.

[76] S.M. Reshetnikov, Acid Corrosion Inhibitors of the Metals (Russ.), Khimia, Leningrad, 1986.

[77] I.L. Rozenfeld, Corrosion Inhibitors (Russ.), Khimia, Moscow, 1977.

[78] A. Popova, M. Christov, A. Vasilev, Inhibitive properties of quaternary ammonium bromides of N-containing heterocycles on acid mild steel corrosion, Part II: EIS results, Corros. Sci. 49 (2007) 3290-3302.

[79] A.M.Al-Sabagh, M. Elsabee, K. Khaled, A.E. Eltabie, Synthesis of Some Surfactants Based on Polytriethanolamine and Investigation of Their Surface Active Properties, J. Disp. Sci. Technol. 31 (2010) 1335-1343.

[80] T.S. Kim, T. Kida, Y. Nakatsuji, T. Hirao, and I. Ikeda, Surface Active Properties of Novel Cationic Surfactants with Two Alkyl Chains and Two Ammonio Groups, J. Am. Oil Chem. Soc. 73 (1996) 907-913.

[81] D.G. Hall, G.J.T. Tiddy, Surfactant Solutions: Dilute and Concentration, in Anionic Surfactants: Physical Chemistry of Surfactant Action, Edited by: E.H. Lucassen-Reynders, Marcel Dekker, New York, Surfactant Science Series, 11, (1981) p. 60.

[82] M.R. Infante, L. Perez, A. Pinazo, Novel Cationic Surfactants from Arginine, in Novel Surfactants, edited by K. Holmberg, Marcel Dekker, New York, Surfactant Science Series, Vol. 74, 1998, p. 97. 
[83] E.W. Anacker, Micelle Formation of Cationic Surfactants in Aqueous Media, in Cationic Surfactants, edited by E. Jungermann, Marcel Dekker, New York, Surfactant Science Series, Vol. 4, 1969, p. 217.

[84] D. Attwood, A.T. Florence, Surfactant Systems: Their Chemistry, Pharmacy, and Biology, Chapman \& Hall, New York, 1983, p 88.

[85] M.J. Rosen, Surfactants and Interfacial Phenomena, John Wiley \& Sons, New York, 1978, pp. 94-95.

[86] N.A. Negm, A.M. Al Sabagh, M.A. Migahed, H.M. Abdel Bary, H.M. El Din, Effectiveness of some diquaternary ammonium surfactants as corrosion inhibitors for carbon steel in $0.5 \mathrm{M} \mathrm{HCl}$ solution. Corros. Sci. 52 (2010) 2122-2132.

[87] W.C. Griffin, Classification of Surface-Active Agents by HLB, J. Soc. Cosmet. Chem. 1 (1949) 311-319. 